\title{
Public Policy, Participation and the Third Position: The Implication of Engaging Communities on their Own Terms
}

\author{
Brian J. Bishop · David A. Vicary • \\ Alison L. Browne · Neil Guard
}

Published online: 28 January 2009

(C) Springer Science+Business Media, LLC 2009

\begin{abstract}
Policy development and implementation should be fundamental for community psychologists in their endeavors to create social change. Policy necessarily is engaged at broad social and political levels, but it is mediated through communities and individuals, and thus appealing for our discipline. We argue that there are increasing opportunities for social input in liberal democracies with the growing awareness of the need to consider social factors in policy. Public participation is one aspect of policy development, but it can be problematic and can disempowered communities, especially disadvantaged communities. Using the framework of the 'third position', a case study of attempts to ameliorate institutional oppression of Australian Aboriginal people through policy change is described. Structural reform to community engagement is described in terms of empowerment and capacity building. Power relationships are deconstructed to allow understandings of the dynamics of policy change, and the broader implications for community psychological praxis are discussed.
\end{abstract}

Keywords Policy · Participation ·

Aboriginal communities $\cdot$ Third position

B. J. Bishop $(\bowtie) \cdot$ D. A. Vicary · A. L. Browne

School of Psychology, Curtin University of Technology,

P.O. Box 1987, Perth, WA 6845, Australia

e-mail: b.bishop@curtin.edu.au

D. A. Vicary

Western Australian Department of Community Development, Perth, WA, Australia

N. Guard

Healthway, Brighton, UK
The involvement of community psychologists in public policy has been advocated since the development of the discipline (e.g., Albee 1959; Bennet et al. 1966; Newbrough 1980; Reiff 1968; Sarason 1974; Syme and Bishop 1993). If community psychology is to deal with social and community level change, then influencing policy and policy makers must be a key element of the discipline. Engaging in policy debate can be done within policy making circles, or as external critic or issues advocate. The former can create unease for community psychologists. "Psychologists, at best, have an ambivalent attitude toward their role in the formulation and implementation of public policy. Cautionary tales of being reduced to political handmaidens, and thus stripped of scientific credibility, stand aside scathing critiques if illinformed social policies that proceeded in ignorance of scientific expertise" (Phillips 2000, p. 398). We will argue that this ambivalence comes from partial understandings of the complexity of policy and social change and that the role of 'participant-conceptualizer', enunciated at the Swamspcott conference (Bennet et al. 1966), provides a basis for a role for community psychologists working on public policy within bureaucracies. We argue that community psychology is ideally placed to increase input into policy making, given its history of multidisciplinary, and theories of empowerment, participation and social change in a domain in which social input is increasingly being sought.

\section{Current Policy Context: The Triple Bottom Line}

In many nations (particularly those with a political system based on Westminster traditions, such as Australia, Canada and England), there has been an increase in consideration of social issues as part of policy (Mahoney and Potter 2004). In Australia, policy considerations have moved 
away from a strong focus on economic considerations to the concept of the triple bottom line (TBL) that encompasses economic, social and environmental components (Mahoney and Potter). Triple bottom line has been embraced by many governments. For example the Government of Australia (2005), p. 1 has stated:

"Triple bottom line (TBL) decision making has become an accepted approach to operationalising the intangible concepts of 'corporate social responsibility' and 'sustainability'. TBL focuses on data collection, analysis and decision making using economic, environmental and social performance information."

This change in government policy and operations offers increased opportunities for participation by social scientists, particularly community psychologists, and importantly, the community. Involvement in policy has paradoxical connotations as policy implementation often has consequences not necessarily envisaged in the political rhetoric of decision makers. Like many group or social paradoxes (Smith and Berg 1997), the paradox can arise out of internal and inherent conflicts in the policy, and in the agencies required to enact the policy. The community psychological orientation has great potential for involvement in TBL decision making due to the emphasis on worldview analysis (Dokecki 1996) and its pragmatic multi-disciplinary history (Rappaport 1977). A major aspect of the role we advocate for community psychologists involves recognizing and understanding the complexity of policy formulation and implementation. This recognition sees policy change processes that can involve broader social change to create more active involvement of communities in decision making of government through empowerment and participation.

One area that incorporates these processes is the relationship between Australian Aboriginal people and government policies, and it is within this area that we explore the opportunities for community psychologists in terms of involvement and participation in cultural policy formulation, and as a metaphor for involvement in policy in general. Specifically, we attempt to show how community psychologists working in policy arenas can create structural change that addresses institutional oppression of minorities using community psychology praxis.

\section{Experiences of Aboriginal Australians and Policy}

According to western genetic research ${ }^{1}$ Australian Aboriginal people were part of the first migration of

\footnotetext{
${ }^{1}$ Australian Aboriginal people dispute the assertions of westernised anthropology. Aboriginal cosmology has it that Aboriginal people have always been in Australia (Atkinson 2002).
}

modern humans out of Africa between 50,000 and 70,000 years ago. They reached Australia some 40,000 50,000 years ago and had been relatively isolated until the arrival of Europeans over two centuries ago (Oppenheimer 2004), at which time there were $\sim 500$ different clan groups, each associated with a different territory, history, dialect and culture (Collard 2000). The British colonized Australia in the late eighteenth century, and since then, Aboriginal people have suffered from oppression and disadvantage. At that time, the dominant view of race and culture was biologically determined (Markus 1994; Sabbioni 1998). This assertion of race as biologically determined, and the assertion that Aboriginal Australians were primitive, uncivilized and were therefore considered to not have any social structures which could have supported formal settlement (Dodson 2002), resulted in Australia being declared 'terra nullius' (empty land). There were an estimated 300,000-700,000 Aboriginal people living across the continent, forming about 500 different 'tribal' and language groups (Collard 2000; Rijavec et al. 1992). The Aboriginal population plummeted to 50,000 by the 1890s through introduced diseases, dispossession of land, massacres and covert frontier wars (Flannery 1994). Current day Aboriginal health and mental health is considerably worse than for non-Aboriginal Australians and while the health of comparable populations in other first world countries have improved, Australian Aboriginal people still fare poorly comparatively (Hunter and Harvey 2002; Zubrick et al. 2004). For example, while the life expectancy of Canadian, USA and New Zealand indigenous peoples is 5-7 years less than their non-Indigenous country people, Aboriginal Australians still die 20 years earlier than non-Aboriginal Australians (Hunter and Harvey).

Governmental policy can be broadly divided into five time frames: protection (1940s-1950s), assimilation (1950s-1970s), integration (1967s-1970s), self-determination (1970-2000), and mutual obligation (2,000+) (Clark 2000). From around the turn of the twentieth century, Aboriginal people began to disappear from historical writings and their 'invisibility' persisted until the 1960s (Reynolds 1998) as a result of colonial and oppressive policies (e.g., Clark). These policies have been the result of paradoxical views of Aboriginal people in the general community; the 'noble savage' and their perception as an inferior race of people requiring protection (Williams 2000), which has led to neglect of human rights and devastated communities (HREOC 1997; Zubrick et al. 2004).

An example of oppressive policy was the forced removal of Aboriginal children from their parents in the first half of the twentieth century. This policy had devastating impacts on the community structure of Aboriginal people and on their physical and mental health (HREOC 
1997). While the policy of forced removal of children was stopped and later condemned as faulty and uncaring (HREOC), the policy is still practiced, but in a more sophisticated manner. In the original policy, the removal of children was based on the initial assumption that the Aboriginal people would die out as a culture and some of the children could be saved by 'making them white'. When the Aboriginal population stopped declining and began increasing, the policy changed to assimilation with the intention of having a homogenous Australian culture. After the policy of forced removal was abandoned, new policies of child protection were developed. Under these, Aboriginal children were removed to foster homes where there was danger from neglect or abuse. These policies are generally not seen as being part of the forced removal policies as the 'children's welfare is primary', but Aboriginal children are still removed at a rate over six times more than nonAboriginal children -23.7 per 1,000 for Aboriginal children in 'out of home care' versus 3.6 per 1,000 for nonAboriginal children (Kim 2005). The policy ignores the broader issue of Aboriginal disadvantage, poverty and systemic government and societal oppression that leads to community breakdown (Garvey 2000a; Gordon 2002) and results in excessive consumption of alcohol and drugs, and physical and sexual abuse. Also underlying these policies are notions of 'whiteness' (Frankenberg 1993, 2001) in which the majority takes for granted privileges denied to minority groups and allows for governmental neglect of sectors of the broader community and "...the production and reproduction of dominance rather than subordination, normativity rather than marginality, and privilege rather than disadvantage" (Frankenberg 1993, p. 236). Thus the policy that is designed to protect the welfare of Aboriginal children continues the policy of forced removal and its impact on Aboriginal culture and community cohesiveness, both of which are cause of considerable concern for Aboriginal people (Dudgeon et al. 2002; Bishop et al. 2006a).

\section{Participation in Policy Formation}

The paradoxical nature of policy means that attempting to change policy presents considerable difficulty. Just as Scribner (1970) argued for a multiplicity of roles for community psychologists, a multiplicity of approaches to policy is necessary. The activist's role is important to critically address the impacts of policy. There is also a role for community psychologists working on policy development within bureaucracies, which she described as 'social engineers', although the subtlety of the vision we have for this role is much greater than implied in her terms. The exploration of policy is framed within a sociopolitical view of social action that emphasizes the interconnections between ideology, culture, institutions, and individuals (see Montero 1990, 2002; Rose 1999; Serrano-Garcia et al. 1987).

Community psychologists working within agencies have opportunity to create considerable change, but need to recognize they have limited power, as policy formulation is influenced by many political and social factors that may or may not be easily accessible to consciousness (Syme and Bishop 1993; Szyliowicz 2003). A necessary component of the role of community psychologists in policy formulation is that of the participant-conceptualizer (Bennet et al. 1966; Reiff 1968), where the community psychologists are able to deconstruct the context and nature of policy, and to inform and affect others involved in policy setting. This process involves deep understand of the nature of multidisciplinary participation (Browne et al. 2005; Stokols 2006), the nature of power, particularly as articulated by Foucault (1991), paradoxes of group decision making (e.g., Smith and Berg 1997), barometers of social change (Sarason 2000), and worldviews (Bishop et al. 2002; Sarason 1981). This role involves being part of an advisory or decision making group, yet being able to deconstruct the functioning of the group and its local and broader social, political and historical context.

Adopting such a role can be difficult for the community psychologist and also those we are working with. As the role involves analysis of the motivations and worldviews of other players, it can be unnerving for all involved, but we argue that it is essential for more effective policy making. Such role could be very challenging for both community psychologists and decision makers, yet there are opportunities for the discipline as the nature of policy setting is changing and there is increased awareness for the need of social input. In the following sections we outline the increased roles for social scientists in policy. We finally provide an example of how a community psychologist can have impacts on policy that are based on a deeper understanding of the historical and political nature of oppression of Aboriginal people.

The rise of the Triple Bottom Line in policy has meant that social scientists have the opportunity for greater input. Issues of empowerment, social capital, community capacity building and public participation have become progressively more invoked in policy development, and are terms not unfamiliar to community psychologists (e.g., Nelson and Prilleltensky 2005; Perkins and Long 2002). Social considerations have been increasingly operationalized as 'community involvement' or public participation (Jones 2005a; Kelsey 2003; Kingma and Beynon 2000, 2001). For example, social impact assessment has moved towards greater public involvement. (Taylor et al. 1990). In other areas of policy development there has also been an 
increase in the participation of community members (e.g., in environmental concerns Peterson et al. 2005; Pretts 2004, in health, Maloff et al. 2000; South 2004, and in Aboriginal health, Cove et al. 1995).

\section{Challenges to Participation}

Operationalizing social input as public participation is not without difficulties. Public involvement is contentious. Arnstein (1969) warned that not all participation is equally engaging and empowering. The nature of participation influences its functioning, utility and outcomes. Vernoy and McDougall (2003) distinguished between functionality and empowerment. However, the most commonly talked about description is participation for instrumental or transformational purposes (Buchy et al. 2000; Nelson and Wright 1995). This description distinguishes participation as being either a tool for a specific end (instrumental participation) or a tool for social change (transformative participation) (Buchy and Race 2001). There are two distinct forms of participation, one as an ideological approach for community development, and the second views participation as a set of guidelines, methods and practices for getting communities and the general public involved in decision making (Buchy and Hoverman 1999). The distinction is essentially between whether the processes of participation are considered to be a means to an end or an end in itself (Buchy and Hoverman; Nelson and Wright). When participation is being used to achieve a specific (possibly non-community directed) end, concerns can be raised regarding the impact of such an approach on communities. In community psychology, the issue of the activist versus the social engineer can be framed in terms of the former being more concerned with empowerment and participation as a tool for social change, and the later more with instrumental purposes.

A fundamental assumption that is rarely articulated in participation is that of the nature and legitimacy of involving the community. These relate to the fundamental nature of governance in (neo) liberal democracies. The assumption that communities have rights to be involved in decision making is often countered by those who assert that democracy involves the election of representatives who do the decision making for the community. Under question is what the nature of 'demos' is. The United States of America's founding fathers were well aware of this contention. James Madison, e.g., advocated for a republic where representatives govern according to a constitution, which provides a framework and limitation of the powers of the state. A fundamental concern is that of protecting the rights of the individual from the majority. The concern here was to limit what de Tocqueville (1988) termed the 'tyranny of the majority'. Furthermore, increased public participation has been argued to directly increase distrust in government (Jones 2005b) and thus present a paradox to decision makers.

Athenian democracy, on the other hand, involved the opportunity for all (males) Athenians to vote and to speak in the Assembly. They did not elect representatives and decision making involved all those who wished to participate. Allport (1948) reflected on Lewin and Dewey's views that democracy was inherently less stable than authoritarian political structures, when he wrote:

"There is a striking kinship between the work of Kurt Lewin and the work of John Dewey. Both agree that democracy must be learned anew in each generation, and that it is far more difficult form of social structure to attain and maintain than autocracy. Both see the intimate dependence of democracy upon social science. Without knowledge of, and obedience to, the laws of human nature in group settings, democracy cannot succeed" (p. x1).

This is related to notions of governmentality (Foucault 1991; Dean 1999). This understanding of government is not the traditional understanding of government and political structures as being the locations of hierarchical power, rather "government entails any attempt to shape with some degree of deliberation aspects of our behaviour according to particular sets of norms and for a variety of ends...an undertaking conducted in the plural. There is a plurality of governing agencies and authorities, of aspects of behaviour to be governed, or norms invoked, of purposes sought, and of effects, outcomes and consequences" (Dean, p. 10).

The comments of Crane et al. (2004), Jones (2005a, b), and Rawsthrorne and Chritian (2005), e.g., reflect the tension between notions of participatory democracy and representative democracy, which impact on the nature of public participation that can be achieved. This tension is also analogous to Tönnies (1988) distinction between Gemeinschaft (the village social structure) and Gesellschaft (the modern society) and the notions of morality that are inherent to these different social structures. He argued that there has been a change in the nature of communities where traditional conceptualizations characterized by communal bonds, morality and sense of membership have shifted to a new society. Society is characterized by modernist principles, where living and membership is individualized. Essentially, western societies have moved from the paradigm of the volkstum (the people) to the stastsum (the state). Here there is decreased importance in traditions, customs and mores. In the development of a city, "individuals or families are separated entities, and their common locale is only an accidental or deliberately chosen place to live" (p. 4). Morality changed from an evolving, contextualized set of mores based on religion and 
responding to local situations, to one where the state sets guidelines for people to live by (although it is the demos that has historically set the rules for the elected representatives to govern by). It is in this political structure that the involvement of Aboriginal people in policy setting can perpetuate paternalism and thus to oppression by neglect and indifference.

The clash of Gemeinschaft morality and that of the Gesellschaft creates differing understandings of what participation means, and this is reflected in practices and policy. This is more fully accentuated and highlighted as industrialization and globalization have lead to the changing nature, definition, and impact of nation states, as practices and policies became influenced significantly by broader international pressures (Kaptein 1993; Rose 1996). There is a strange contradiction here as national borders become more permeable, both Gesellschaft influences and Gemeinschaft influences in democracies and other governmental structures across the world become highlighted and incorporated into traditional nation state governments such as in Australia.

A resolution to this issue has been suggested by Newbrough $(1992,1995)$. He synthesized the work of Tönnies, Dewey (1927) and Kirkpatrick (1986) to reframe Gemeinschaft and Gesellschaft as 'the one' and 'the many', respectively. He argued that community psychologists need to work towards creating a 'third position' which based on post-modern thinking was characterized as 'the one and the many'. The third position involves creating change to Gesellschaft to accommodate Gemeinschaft characteristics. The third position would entail greater local citizen participation in decision making in community life. Participation has been seen as central to empowerment (Perkins and Zimmerman 1995). In the third position, participation is the key to integrating sense of community and ownership of the change processes. Without recognition of the need for change a paradox is still present, and this is more evident when the policy domain involves Aboriginal people, given their greater sense of community (Dudgeon et al. 2002).

Public involvement is not a simple approach that will ensure better decision making. The process is set in a broader historical climate in which democratic values are difficult to define, to maintain, and are viewed increasingly with greater community skepticism. The debate over the merit of community involvement is still intense. Community psychological input could well be founded on the value of empowering people. A more important corollary of public involvement is that it allows a better understanding of the social phenomena that the policies are meant to be addressing. We would argue that the role of the community psychologist is to deconstruct the nature of policies in their broader social context, in which the issues of governmentality, democracy, historical and current practices of oppression and empowerment are set against the new. In doing so, the complex and fluid nature of power can be seen. Returning to Aboriginal policy Morris (1989), made the following point:

"Over time, there was a gradual shift away from punitive and isolationist approach to dealing with Aboriginal people to an ostensibly protectionist and pastoral approach. The irony is that under the new policy regime, there was more control of Aboriginal people's lives, and probably more abuse" (p. 111).

In the following section, we explore a research project designed to look at how Aboriginal communities may better access governmental funding. We present the research and then deconstruct the power issues involved.

\section{Western Australian Governmental Cultural Grants Review}

As a result of the continued oppression of Aboriginal people, there is considerable mistrust of non-Aboriginal people, particularly governments, government agencies (police and social welfare, for example) and researchers (Garvey 2000b; Smith 1999; Vicary and Bishop 2005). Aboriginal people have become increasingly wary and resistant to being involved in research conducted by nonAboriginal people, even when the research may appear to have direct benefit to the participants and their communities. One such research project, the Cultural Grants Review (CGR) was conducted by the Office of Children and Youth (OCY) of the Department of Community Development (DCD) and Healthway, a government funding agency (Vicary et al. 2004). The Western Australian Government offers a range of grants and funding to community organizations. The CGR examined grants offered by OCY and Healthway from a culturally appropriate, secure, sensitive and pragmatic orientation.

The CGR is unique in that it was designed, implemented and completed by a group of community psychologists (led by the second author) and an Aboriginal Steering Group. The rigor and cultural sensitivity brought to the project by this group, was and continues to be, unusual in government settings. The methodological model used by the group evolved from doctoral community psychology research and refinements developed by the authors (Bishop et al. 2006b). The project was designed to identify why Aboriginal people did not participate in the application process for OCY and Healthway funding and to develop procedures that would allow them to access funding for community projects.

To an outsider, the possibilities of this research proceeding were not great. DCD had been responsible for the 
forced removal of Aboriginal children in the period from the turn of the twentieth century to the mid 1960s. As mentioned earlier, the policy of forced removal was based on past policies that initially assumed that Aboriginal people would die out and that the lighter skinned children could be raised in the predominantly white community. When Aboriginal population started to increase, the policy was changed to that of assimilation, and the forced removal practices were maintained. As DCD was responsible for the enactment of this policy, there was widespread distrust of the department within Aboriginal communities.

Aboriginal people may find themselves disadvantaged in trying to access funding opportunities due to their geographical and/or social isolation, lack of information about grants and granting processes, reduced social capital and infrastructure, and culturally insensitive grant practices. Many funding organizations within Australia specifically target Aboriginal communities as potential applicants. However, few funding organizations are successful in meeting their predicted funding outcomes to these communities due to poor uptake of applications by the target groups. Importantly, the paucity of applications led the second author to review his organizations' funding practices and resulted in the research outlined below. This review of policy and practice is consistent with the TBL and well entrenched community psychological participatory methods. Both OCY and Healthway have identified that a limited number of applications are received from Aboriginal organizations and jointly undertook this review to determine if the then current funding practices were meeting the needs of the community and if there were any recommendations for improving the process. In essence, this research was designed to ask Aboriginal people how they viewed the current grant processes used by both the OCY and Healthway to identify recommendations for improvement. It was hoped that the cultural grants review could contribute knowledge to a range of governmental and non-governmental bodies that make funding available to Aboriginal communities so that a more culturally secure practice can be adopted.

\section{Cultural Grants Research Process}

The cultural grants review included three qualitative data collection techniques. These included an archival review of current and past policies, focus group feedback and client interviews. Qualitative informative methods were selected for this review as they have been identified in previous research as the most appropriate in consulting with Aboriginal people (Bishop et al. 2006b). The cultural grants review was undertaken by two senior Aboriginal staff from OCY. These officers were guided by a project steering group that was made up of Aboriginal people from government, not-for-profit and private sectors across Western Australia. The steering group believed that given their own areas of expertise and work experience, they would be able to 'vouch' for the project. Being vouched for by a group of well-known and significant Aboriginal people was a way of expediting engagement with potential participants. The semi-structured interview schedule and a questionnaire used in the study were developed in close conjunction with the Aboriginal steering group. Workshops were used to pilot the methods with a group of Aboriginal youth and workers in the metropolitan area. The pilot group involved valuable feedback on interview processes and the workshop format, and were ultimately used across the state for all communities. This allowed for the results to be collated in a consistent manner.

The workshops were specifically designed by and targeted towards Aboriginal people. All the workshops were conducted by experienced and trained staff from the OCY. Participants in the workshops were treated in an equalitarian manner in which issues of power differentials were addressed and the workshops were conducted in an informal manner that was respectful of Aboriginal culture. Workshop facilitators and interviewers had to be trained in adopting Aboriginal ways of working, as their expectations of 'research' and the bureaucratic socialization they had experienced meant that they felt they had to be formal, rather than use their own cultural knowledge. Training people to recognize the impacts bureaucratic settings have on dehumanizing people's interactions and to be able to treat people the way we would want to be treated is not easy and requires considerable effort (Goldenberg 1971). As the intent of the researchers was to establish long-term sustainable relationship, considerable concern had to be taken to address power imbalances and cultural sensitivities, as prior experience with government agencies and the typical short-term issues with university-based research had created considerable resistance to participation. The result was a group of people committed to the project and keen to ensure its success. Many of them continue to maintain their relationship with OCY.

In all, 428 people participated off whom 327 were of Aboriginal or Torres Strait Islanders descent. The remainders were non-Aboriginal people. The majority of participants were from non-metropolitan areas $(n=363)$ and 65 were from the Perth metropolitan area. Slightly more females $(53 \%)$ participated than males.

\section{Evolving Outcomes}

The archival review was used to identify where culturally sensitive funding processes had been used in Western Australia and elsewhere. No culturally secure Western 
Australian policies, forms or procedures were found for processing or evaluating funding applications from Aboriginal communities or individuals, although the Western Australian government has culturally sensitive policies on engaging with Aboriginal communities (Government of Western Australia 2003). However, it was discovered that some organizations offered very good telephone and internet support in completing applications.

It is important to note that one broad conclusion of this research is that the current grant policies are culturally inappropriate and this maintains oppression at a structural level. The current policies are culturally appropriate for mainstream non-Aboriginal people, but create impediments for Aboriginal people. These problems can be exacerbated by the physical remoteness of many communities, which make it more difficult to hear about, and access, grants.

The main findings of the research were that funding agencies needed to adopt procedures that were culturally sensitive and safe for Aboriginal communities. It was also found that grants processes needed to be changed to improve uptake by Aboriginal people, particularly young people. Many reported that they found the grant process time-consuming and challenging, particularly if they were dealing with other crises in their lives and/or community. Given the discussion of the cumulative impact of past policies and oppression in Australia, the issues of 'crises' is particularly important. An inability to connect with current grants policies should be viewed as personal, familial and community crises whose genesis may be the oppressive history.

Ninety percent of the large organizations consulted felt that once-off grants for small amounts of money can be a burden on communities due to the effort and resources required to apply for, and acquire the funding. A number of Aboriginal community organizations reported that small grants are often jointly funded by a number of agencies. Having a multiplicity of agencies that a community has to report to can make the process bureaucratically complicated. These organizations advocated for a more streamlined and coordinated approach. Also, a major issue was that of the nature of the funding application. In the past, all applications had to be written. It was recommended that the funding application processes should allow for a variety of different formats including written, video and oral applications. All of these applications would follow the same format and require the same information. However the video and oral application could be done without the arduous written component. This recommendation has since been adopted by both OCY and Healthway, who are now receiving video and oral applications along with more streamlined written applications. The first video application received was from one of the most remote and isolated Aboriginal communities in
Australia. This community's application was successful. All recommendations made in the report have been adopted by both OCY and Healthway and this has resulted in significant alterations to practice. Other funding organizations (state, national and international) have demonstrated considerable interest in the CGR and the recommendations made from it. Consequently, some of these agencies are currently reviewing their own practices from a culturally secure orientation.

Finally, it is very important to recognize that in the climate of hostility towards research and researchers, the extent of participation, particularly by youth, in this research was quite dramatic. Some interviews lasted up to $4 \mathrm{~h}$. This is not consistent with the zeitgeist in the area of Aboriginal research at the moment where there is a great reluctance of Aboriginal communities to be involved. The main reason for this appears to be the willingness of the departments involved to actually engage the community in their own terms, and not in the terms of the culture of the bureaucracies, as well as the departmental commitment to implementing the recommendations from this participatory practice in a way that creates structural change.

\section{Lessons Learned}

In deconstructing the Cultural Grants Review it is very important to recognize that there was a structural change occurring in the research process at a number of levels. Not only were the outcomes recommending structural changes in the way in which Aboriginal people can apply for funding, but in the research process itself. This represents a structural change to the way Aboriginal people are engaged, through a process of empowerment (e.g., Rappaport 1981), capacity building (e.g., Chinman et al. 2005) in culturally respectful ways (e.g., Reich and Reich 2006). The research was conducted by Aboriginal staff in Aboriginal terms, and was overseen by an Aboriginal steering committee. This process gave Aboriginal people considerable control over the research agenda and methods. The research process was not only culturally sensitive to Aboriginal people at the interview level, but also empowered them as individuals. Interviews were conducted as 'yarning' or in an informal manner that was consistent with Aboriginal culture and mores (Bishop et al. 2006b). The research model was determined and controlled by Aboriginal people rather than using traditional methods adopted by western science. This is not simply a methodological change but represents a significant change in the orientation of the departments towards doing business. The bureaucracies recognized they needed to change their practices and this reflects a considerable change in the thinking of the organizations. This was post-modern 
thinking as articulated by Newbrough (1992). It involves recognition that the bureaucracies are part of the problem they are trying to solve and that they needed to change their power relations with the communities they were trying to serve.

The research itself needs to be seen in much broader terms simply using culturally appropriate methods to increase its efficiency (Donovan and Spark 1997). There is considerable literature, particularly in the public health area, that suggests that research with Aboriginal people needs to be much more culturally sensitive (e.g., Grove et al. 2003; Humphrey 2001; Todd et al. 2000). The issues here are not simply to improve the research process by increasing its cultural sensitivity. The problem with seeing the research process in purely culturally sensitive terms indicates that in fact the researchers' agendas still have priority. What Donovan and Spark basically were suggesting is that we need to increase the cultural sensitivity of the research process to ensure that we get a reasonable sample size; that is we need to be culturally sensitive to meet our research needs. This is an example of instrumental rather than transformative participation (Buchy and Race 2001). In the research program we have discussed here, the departments involved were prepared to create change at a structural and organizational level to ensure that they did their job properly with, and for, Aboriginal people, not just to meet their own research needs. The structural change is an essential aspect of the process. Smith (1999) had indicated that the models of researching people from indigenous communities adopted by westerners are inherently colonial. In this research, this colonial structure was recognized and the research model was negotiated with the communities, in a successful attempt to use participation as a transformative element in 'decolonizing' organizational structures and practices.

The nature of the Aboriginal communities' participation in the research was a fundamental shift from participatory models traditionally enacted by governments. It involved the bureaucracies changing their power relationships and moving from the role of experts providing services to one in which the Aboriginal communities were involved in setting the way in which the services were to be provided. This shift in power has considerable importance beyond this arena. It has considerable symbolic value for Aboriginal communities and to the concepts of governmentality in general. It is a move towards Newbrough's (1995) third position, an approach that addresses the tension between representational governance and democratic governance as it shifts the nature of the roles of the community and service providers. This change is not a threat to the existing governance structures, but redefines their roles. The community now has input into how services can be effectively provided. It is not a threat as government and bureaucracies still make policy, decisions and provide services, but in a fashion that will be more effective and in line with the aspirations of communities.

The new policy process evidenced by the Cultural Grants Review process involves integration of policies, programs and practice in which community participation for the end of transformative structural change is central, even within a system bounded by the constraints of globalization and representative democratic values. Conceptually, this is an empowering process that involves social change towards what Newbrough (1995) called the 'one and the many'; a structure where people are actively engaged in decision making in policy that directly affects their daily lives and well-being. It involves the bureaucracy creating space in the Gesellschaft structure for Gemeinschaft participation, or in Newbrough's terms, allowing the one to exist in the many. The one and the many have the potential to address the decay of sense of community (Sarason 1974) by creating a model of society in which community can be nurtured while bureaucracy maintains structure and provides services.

\section{Conclusion}

Community psychologists are well placed to engage in policy development, particularly when there is an emphasis on TBL outcomes (e.g., policy, programs and practice). The concepts of contextualism (e.g., how we treat people and the role of psychology as a method of creating social justice and change is clearly based and articulated from community experience), social change, empowerment and participation and the sensitivity to social processes and change are necessary for an understanding of the multileveled nature of policy implementation. The recognition of ecological levels fits well with the understanding that policy is formulated at one level, operationalized at another and implemented at a third level.

Community participation in decisions that affect them is becoming the norm and its value is being recognized in policy development. In many cases, this participation in premised on the concepts of the triple bottom line and the idea of social sustainability. However, experience has demonstrated that ensuring practical outcomes that benefit communities is sometimes difficult to achieve as the guiding Gesellschaft elements that drive the system reproduces themselves. In order to achieve realistic and pragmatic outputs, researchers, policy makers and practitioners must work together to ensure a fluid and seamless uptake of theory, policy interpretation and practice implementation in a manner designed to incorporate the one and the many. This method should be reciprocal, dynamic and iterative in nature. Community psychologists, as a part of these systems must embrace these processes to turn both 
the theoretical and policy rhetoric into tangible realistic service delivery outcomes.

\section{References}

Albee, G. W. (1959). Mental health manpower trends. New York: Basic Books.

Allport, G. W. (1948). Foreword. In K. Lewin \& G. W. Lewin (Eds.), Resolving social conflicts; selected papers on group dynamics (pp. vii-xix). New York: Harper \& Row.

Arnstein, S. R. (1969). Eight rungs on the ladder of citizen participation. Journal of the American Institute of Planners, $35,217-223$.

Atkinson, J. (2002). Trauma trails, recreating song lines: The transgenerational effects of trauma in Indigenous Australia. Melbourne: Spinifex.

Bennet, C. C., Anderson, L. S., Cooper, S., Hassol, L., Klein, D. C., \& Rosenblum, G. (Eds.). (1966). Community psychology: A report of the Boston conference on the education of psychologists for community mental health. Boston: Boston University Press.

Bishop, B. J., Sonn, C. S., Drew, N. M., \& Contos, N. E. (2002). The evolution of epistemology and concepts in an iterative-generative reflective practice: The importance of small differences. American Journal of Community Psychology, 30, 493-510.

Bishop, B. J., Colquhoun, S. D., \& Johnson, J. (2006a). Psychological sense of community: An Australian Aboriginal experience. Journal of Community Psychology, 34, 1-7.

Bishop, B. J., Vicary, D. A., Andrews, H., \& Pearson, G. (2006b). Towards a culturally appropriate mental health research process for Indigenous Australians. Australian Community Psychologist, 18(2), 31-41.

Browne, A. L., Bishop, B. J., \& Dzidic, P. (2005). Adopting 'holistic' research methodologies: An introduction. ACQ, 7, 102-105.

Buchy, M., \& Hoverman, S. (1999). Understanding public participation in forest planning in Australia: How can we learn from each other? (Occassional Paper No. 99.2). Canberra: Australian National University, School of Resources, Environment and Society, Forestry.

Buchy, M., \& Race, D. (2001). The twists and turns of community participation in natural resource management in Australia: What is missing? Journal of Environmental Planning and Management, 44, 293-308.

Buchy, M., Ross, H., \& Proctor, W. (2000). Enhancing information base on participatory approaches in Australian natural resource management. Canberra: The Australian National University.

Chinman, M., Hannah, G., Wandersman, A., Ebener, P., Hunter, S. B., Imm, P., et al. (2005). Developing community science research agenda for building community capacity for effective preventive interventions. American Journal of Community Psychology, 35, 143-157.

Clark, Y. (2000). The construction of Aboriginal identity in people separated from their families, community, and culture: pieces of a jigsaw. Australian Psychologist, 35, 150-157.

Collard, K. (2000). Aboriginal culture. In P. Dudgeon, D. Garvey, \& H. Pickett (Eds.), Working with Indigenous Australians: A handbook for psychologists (pp. 21-26). Perth: Gunada.

Cove, D., Contos, N., Mayall, T., \& Bishop, B. J. (1995). Hall's Creek community health plan report. Derby, Australia: Northern Health.

Crane, A., Matten, D., \& Moon, J. (2004). Stakeholders as citizens? Rethinking rights, participation, and democracy. Journal of Business Ethics, 53, 107-122.

de Tocqueville, A. (1862/1988). Democracy in America (trans: Reeve, $H$.). London: Longman, Green, Longman \& Roberts.
Dean, M. (1999). Governmentality: Power and rule in modern society. London: Sage.

Dewey, J. (1927). The public and its problems. New York: Henry Holt.

Dodson, M. (2002). Sovereignty. Balayi: Culture, Law and Colonialism, 4, 13-19.

Dokecki, P. R. (1996). The tragi-comic professional: Basic considerations for ethical reflective-generative practice. Pittsburgh, Pennsylvania: Duquesne University Press.

Donovan, R. J., \& Spark, A. (1997). Towards guidelines for survey research in remote Aboriginal communities. Australian and New Zealand Journal of Public Health, 21, 85-95.

Dudgeon, P., Mallard, J., Oxenham, D., \& Fielder, J. (2002). Contempory Aboriginal perceptions of community. In A. T. Fisher, C. C. Sonn, \& B. J. Bishop (Eds.), Psychological sense of community: research, applications and implications (pp. 223246). New York: Kluwer Academic/Plenum.

Flannery, T. F. (1994). The future eaters: an ecological history of the Australasian lands and people. Melbourne: Reed.

Foucault, M. (1991). Governmentality. In G. Burchell, C. Gordon, \& P. Miller (Eds.), The Foucault effect: Studies in governmentality. Chicago: University of Chicago Press.

Frankenberg, R. (1993). White women, race matters: The social construction of whiteness. Minneapolis: University of Minnesota Press.

Frankenberg, R. (2001). The mirage of an unmarked whiteness. In B. Bander Rasmussen, E. Klinenberg, I. J. Nexica, \& M. Wray (Eds.), The making and unmaking of whiteness (pp. 72-96). Durham, NC: Duke University Press.

Garvey, D. (2000a). A response to the Australian Psychological Society discussion paper on suicide. Australian Psychologist, 35, $32-35$.

Garvey, D. (2000b). Communicating with Torres Strait Islander people. In P. Dudgeon, D. Garvey, \& H. Pickett (Eds.), Working with Indigenous Australians: A handbook for psychologists (pp. 219-224). Perth: Gunada.

Goldenberg, I. I. (1971). Build me a mountain: youth, poverty, and the creation of new settings. Cambridge: MIT.

Gordon, S. (2002). Putting the picture together: Inquiry into response by Government agencies to complaints of family violence and child abuse in Aboriginal communities. Perth: State Law Publisher.

Government of Australia. (2005). Prime Minister's community business partnership. Canberra: Government of Australia. Retrieved November, 2005, from http://partnerships.gov.au/ links/tmpblihs5ltcd.htm.

Government of Western Australia. (2003). Consulting citizens: Engaging with aboriginal Western Australians. Retrieved May, 2005, from http://www.citizenscape.wa.gov.au/index.cfm? event $=$ ccuPublications.

Grove, N., Brough, M., Canuto, C., \& Dobson, A. (2003). Aboriginal and Torres strait Islander health research and the conduct of longitudinal studies (issue for debate). Australian and New Zealand Journal of Public Health, 27, 637-641.

Human Rights and Equal Opportunity Commission. (1997). Bringing them home: National enquiry into the separation of Aboriginal and Torres Strait Islander children from their families. Canberra: Australian Institute of Aboriginal and Torres Strait Islander Studies.

Humphrey, K. (2001). Dirty questions: Indigenous health and 'Western research'. Australian and New Zealand Journal of Public Health, 25, 197-202.

Hunter, E., \& Harvey, D. (2002). Indigenous suicide in Australia, Canada, New Zealand and the United States. Emergency Medicine, 14, 14-23. 
Jones, G. T. (2005a). Making community engagement responsible. Proceedings of the international conference on engaging communities. Brisbane, August. Retrieved November, 2005, from http://engagingcommunities2005.org/home.html.

Jones, G. T. (2005b). Participatory democracy: cracks in the façade. Proceedings of the international conference on engaging communities. Brisbane, August. Retrieved November, 2005, from http://engagingcommunities2005.org/home.html.

Kaptein, E. (1993). Neo-liberalism and the dismantling of corporatism in Australia. In H. Overbeek (Ed.), Restructuring hegemony in the global political economy: The rise of transnational neoliberalism in the 1980s (pp. 79-109). New York: Routledge.

Kelsey, E. (2003). Constructing the Public: Implications of the discourse of international environmental agreements on conceptions of education and public participation. Environmental Education Research, 9, 403-427.

Kim, C. (2005). Children, youth and families. A paper presented at the Australia's welfare 2005 conference. Canberra, November. Retrieved from the proceedings at January, 2006, http://www. aihw.gov.au/eventsdiary/aw05/program.cfm.

Kingma, O., \& Beynon, N. (2000). It can't work without people: Conceptual frameworks for analysing effective relationships between players in natural resources management (Final report for research project No. CAG2). Canberra: Capital Agricultural Consultants and Land \& Water Australia.

Kingma, O., \& Beynon, N. (2001). It can't work without people: Effective relationships in natural resource management (Fact sheet for research project No. CAG2). Canberra, Australia: Land $\&$ Water Australia, Social and Institutional Research Program.

Kirkpatrick, F. G. (1986). Community: A trinity of models. Washington, DC: Georgetown University Press.

Mahoney, M., \& Potter, J.-L. (2004). Integrating health impact assessment into the triple bottom line concept. Environmental Impact Assessment Review, 24, 151-160.

Maloff, B., Bilan, D., \& Thurston, W. (2000). Enhancing public input into decision making: Development of the Calgary Regional Health Authority public participation framework. Family \& Community Health, 23, 66-78.

Markus, A. (1994). Australian race relations. Sydney: Allen \& Unwin.

Montero, M. (1990). Ideology and psychosocial research in third world contexts. Journal of Social Issues, 46(3), 43-55.

Montero, M. (2002). On the construction of reality and truth. Towards an epistemology of community social psychology. American Journal of Community Psychology, 30, 571-584.

Morris, B. (1989). Domesticating resistance: The Dhan-gadi Aboriginals and the Australia state. Oxford: Berg.

Nelson, G., \& Prilleltensky, I. (Eds.). (2005). Community psychology: in pursuit of liberation and well-being. New York: Palgrave Macmillan.

Nelson, N., \& Wright, S. (1995). Participation and power. In N. Nelson \& S. Wright (Eds.), Power and participatory development: Theory and practice (pp. 1-18). London: Intermediate Technology.

Newbrough, J. R. (1980). Community psychology and the public interest. American Journal of Community Psychology, 8, 1-17.

Newbrough, J. R. (1992). Community psychology in the postmodern world. Journal of Community Psychology, 20, 10-25.

Newbrough, J. R. (1995). Toward community: A third position. American Journal of Community Psychology, 23, 9-37.

Oppenheimer, S. (2004). Out of Eden: The peopling of the world. London: Robinson.

Perkins, D. D., \& Long, D. A. (2002). Neighborhood sense of community and social capital: a multi-level analysis. In A. T. Fisher, C. C. Sonn, \& B. J. Bishop (Eds.), Psychological sense of community: Research, applications and implications (pp. 291319). New York: Kluwer Academic.

Perkins, D. D., \& Zimmerman, M. (1995). Empowerment theory, research and application. American Journal of Community Psychology, 23, 569-580.

Peterson, M. N., Peterson, M. J., \& Peterson, T. R. (2005). Conservation and the myth of consensus. Conservation Biology, 19, 762-767.

Phillips, D. A. (2000). Social policy and community psychology. In J. Rappaport \& E. Seidman (Eds.), Handbook of community psychology (pp. 397-419). New York: Kluwer Academic/ Plenum.

Pretts, J. (2004). Enhancing public input into decision making: Development of the Calgary Regional Health Authority public participation framework. Journal of Risk Research, 72, 115-133.

Rappaport, J. (1977). Community psychology: Values, research and action. New York: Holt, Rinehart and Winston.

Rappaport, J. (1981). In praise of paradox: A social policy of empowerment over prevention. American Journal of Community Psychology, 9, 1-26.

Rawsthrorne, M. \& Chritian, F. (2005). Government/community sector compacts: 'real engagement?'. Proceedings of the International Conference on Engaging Communities. Brisbane, August. Retrieved November, 2005, from http://engaging communities2005.org/home.html.

Reich, S. M., \& Reich, J. A. (2006). Cultural competence in interdisciplinary collaborations: a method for respecting diversity in research partnerships. American Journal of Community Psychology, 36, 51-62.

Reiff, R. (1968). Social intervention and the problem of psychological analysis. American Psychologist, 23, 524-531.

Reynolds, H. (1998). This whispering in our hearts. Melbourne: Allen \& Unwin.

Rijavec, F. (Director/Producer/Script), Harrison, N. (Co-director). (1992). Exile and the Kingdom [Motion picture documentary]. Western Australia: Snakewood Films.

Rose, N. (1996). Governing "advanced" liberal democracies. In A. Barry, T. Osborne, \& N. Rose (Eds.), Foucault and political reason (pp. 37-64). London: UCL Press.

Rose, N. (1999). Powers of freedom: Reframing political thought. Cambridge: Cambridge University Press.

Sabbioni, J. (1998). Preface. In J. Sabbioni, K. Schaffer, \& S. Smith (Eds.), Indigenous Australian voices: A reader (pp. xix-xxxi). New York: Rutgers University Press.

Sarason, S. B. (1974). The psychological sense of community: Prospects for community psychology. San Francisco: JosseyBass.

Sarason, S. B. (1981). Psychology misdirected. New York: Free Press.

Sarason, S. B. (2000). Barometers of community change: Personal reflections. In J. Rappaport \& E. Seidman (Eds.), Handbook of community psychology (pp. 919-929). Kluwer Academic/Plenum: New York.

Scribner, S. (1970). What is community psychology made of? In P. E. Cook (Ed.), Community psychology and community mental health: Introductory readings (pp. 13-20). San Francisco: Holden-Day.

Serrano-Garcia, I., Lopez, M. M., \& Rivera-Medina, E. (1987). Toward a social-community psychology. Journal of Community Psychology, 15, 431-446.

Smith, L. T. (1999). Decolonizing methodologies: Research and Indigenous peoples. London: Zed Books \& University of Otago Press.

Smith, K. K., \& Berg, D. N. (1997). Paradoxes of group life: Understanding conflict, paralysis, and movement in group dynamics. San Francisco: Jossey-Bass. 
South, J. (2004). Rising to the challenge: A study of patient and public involvement in four primary care trusts. Primary Health Care Research and Development, 5, 125-134.

Stokols, D. (2006). Toward a science of transdisciplinary action research. American Journal of Community Psychology, 38, 63-77.

Syme, G. J., \& Bishop, B. J. (1993). Public psychology: Planning a role for psychology. Australian Psychologist, 28, 45-51.

Szyliowicz, J. S. (2003). Decision-making, intermodal transportation, and sustainable mobility: Towards a new paradigm. International Social Science Journal, 55, 185-197.

Taylor, C., Bryan, C., \& Goodrich, C. (1990). Social assessment: Theory, process and techniques. Canterbury: Centre for Resource Management.

Todd, A. L., Frommer, M. S., Bailey, S., \& Daniels, J. L. (2000). Collecting and using Aboriginal health information in New South Wales. Australian and New Zealand Journal of Public Health, 24, 378-381.

Tönnies, F. (1957). Community and society: Gemeinschaft and Gesellschaft (trans: Loomis, C. P.). Michigan: Michigan State University Press.
Vernoy, R., \& McDougall, C. (2003). Principles for good practice in participatory research: Reflecting on lessons from the field. In B. Pound, C. McDougall, \& A. Braun (Eds.), Managing natural resources for sustainable livelihoods: Uniting science and participation (pp. 113-141). London: Earthscan Publications and International Development Research Centre.

Vicary, D. A., \& Bishop, B. J. (2005). Western psychotherapeutic practice: Engaging Aboriginal people in culturally appropriate and respectful ways. Australian Psychologist, 40, 8-19.

Vicary, D. A., Stilling, J., O’Meara, M., Garvie, T., Guard, N., \& Cronin, J. (2004). Cultural grants review. Perth: Office for Children \& Youth, \& Healthway.

Williams, R. (2000). Why should I feel guilty? Reflections on the workings of guilt in white-Aboriginal relations. Australian Psychologist, 35, 136-142.

Zubrick, S. R., Lawrence, A. M., Silburn, S. R., Blair, E., Milroy, H., Wilkes, T., et al. (2004). The Western Australian Child Health Survey: the health of Aboriginal children and young people. Perth: Telethon Institute for Child Health Research. 